\title{
PhD Media: Community, Connection and Communication through Disintermediated Platforms
}

\author{
Tara Brabazon ${ }^{1}$ \\ ${ }^{1}$ Dean of Graduate Research, Flinders University, Australia \\ Correspondence: Tara Brabazon, Flinders University, Australia. \\ Email: tara.brabazon@flinders.edu.au
}

Doi: $10.23918 /$ ijsses.v7i2p13

\begin{abstract}
The term PhD Media activates action. It is an enabling phrase, concept and trope. As a subset of Media Studies and building relationships with higher education studies, this post-disciplinary article deploys learning-led research to align community, communication and connection. An array of proxies - such as attrition, long candidatures and rescue supervisions - are used to illustrate that ineffective and concerning practices are emerging in doctoral education. Yet each student fears, concerns and failures are individualized. Their problems are atomized. This means that for generation after generation, cohort after cohort, expansive institutional issues emerging in international higher degrees are sliced away from educational structures and land on an individual and their personal responsibilities, feeding the deficit model of teaching and learning. Media hold a role in such a process. Media are andragogical. They teach viewers and listeners about normative truths and expectations. This article uses the andragogical capacity of visual media to build a $3 \mathrm{C}$ model of doctoral education: community, communication and connection.
\end{abstract}

Keywords: Doctoral Studies, Higher Degree Studies, Higher Education Studies, Media Studies, Phd Media

\section{Introduction}

The Doctor of Philosophy is a space where experiential ideologies too often trump expertise. "When I did my $\mathrm{PhD}$ " is code for a dismissal of learning-led research, research-based learning, internationalization, regulation, governance and professional development. A single data point - one person's candidature becomes more meaningful in configuring an advisor or supervisor's development than other less impersonal, refereed and verified sources. When the phrase "when I did my PhD" was entered into Google, 107,000 results were returned (Google, 2020).

How do these individual stories connect with wider narratives of doctoral education? Further, what are the consequences of this data sample - of one - on the contemporary higher degree student? More $\mathrm{PhD}$ students are enrolled today, than in any other point in history. This cohort of $\mathrm{PhD}$ students has never been more diverse in age, gender, sexuality, geographical location, dis/ability and class. Therefore, at this very precise moment in history, when the widening participation agenda, the knowledge economy, and a precariat workforce align into a bundle of insecurity and instability, what is the value of an individual's experience from the 1990s, 1980s, or even 1970s? Such simplistic transferability becomes more serious when realizing that individual experience - when cloaked in the word 'supervisor' or 'advisor' - is repeated and acknowledged as inherently valuable, without recognizing the changing sociology and history of higher degrees. It is easier to repeat mistakes than to critique behaviour and question the truths emerging through our adult lives. Indeed, without external commentary, education and critique, mistakes may not even be recognized. Homology is a brutalizing mistress. 
This article summons a phrase, concept and trope: "PhD Media." As a subset of Media Studies and building relationships with higher education studies, this post-disciplinary article deploys learning-led research to align community, communication and connection. Recent studies have confirmed the scale of mental health concerns emerging through the PhD (Levecque, Anseel, De Beuckelaer, Van der Heyden, $\&$ Gisle, 2017). Scholars locate isolation, anxiety and depression. An array of proxies - such as attrition, long candidatures and rescue supervisions - illustrate that ineffective and concerning practices are emerging in doctoral education. Yet each student is individualized. Their problems are atomized. This means that for generation after generation, cohort after cohort, expansive institutional issues emerging in international higher degrees are sliced away from educational structures and land on an individual and their personal responsibilities, feeding the deficit model of teaching and learning (Brabazon, 2018). Media hold a role in such a process. Media are andragogical. They teach viewers and listeners about normative truths and expectations. While media generally - and popular culture specifically - are the hegemonic engine room of democracy, when fuelled by fragmented social media, inconvenient and difficult knowledges and critiques bubble into our reality. Therefore, this article uses the andragogical capacity of visual media to build a $3 \mathrm{C}$ model of doctoral education: community, communication and connection.

\section{Community, Communication and Connection}

The Dean of Graduate Research, and its attendant titles of Dean of Graduate Studies or Students, is a singular position in a university. Requiring research and teaching expertise, it is housed in the Deputy Vice Chancellor - or Provost - portfolio for research. Yet from this research context, the teaching - or research training - of students is required. It is a whole-of institution position, requiring the management of students and supervisors, national legislation, university policies and procedures, and disparate goals and / or Key Performance Indicators in departments, schools, colleges or facilities. Disciplinary silos are particularly challenging to manage, with international research evaluation systems such as the Excellence in Research Australia (ERA) and the Research Excellence Framework (REF) reinforcing the parameters, boundaries and limitations of knowledge and the peer review systems that evaluate it. Original research - let alone the students who create it - rarely fit into categories configured by disciplinary gatekeepers.

The institutional frame around $\mathrm{PhD}$ programmes is also troubling. Much is problematic in the contemporary university. Indeed "Critical University Studies" features monograph titles dominated by the word 'crisis' and even 'zombies' (Whelan, Walker, \& Moore, 2013). This crisis has many causes and origins but is fuelled by a lack of purpose. For every vision statement and strategic plan, there is a lack of content about the meaning, propulsion and trajectory of teaching, learning and research. This 'crisis' has a profound impact on doctoral education. The assumptions about $\mathrm{PhD}$ students and the degree in which they have enrolled are challenging when configuring policy priorities and institutional and national alignments. Supervisors/advisors have expectations about standards, the scope and scale of reading, the calibre of writing and, more controversially, their right to authorship to student articles. Students maintain divergent expectations about their candidature and career. These divergent assumptions create an array of problems, including high levels of attrition. But also, the expected pathway of an academic career from a doctorate - that has not been a normative conduit for decades - no longer exists. The supposed 'end point' of a $\mathrm{PhD}$ is a brick wall, not a footpath. A diversity of public and private, consultancy and gig economy careers, now emerge from a PhD. Further, with the increasing age of doctoral candidates enrolling in part- 
time degrees to change or enhance their existing career, students do not leave or enter employment, but use the $\mathrm{PhD}$ for personal interest or to enact promotional opportunities and expertise.

Recognizing this diversity, building links and relationships between students is crucial, but challenging. The key when formulating a communication system for doctoral candidates is the integration of learningled research and research-based learning into the $\mathrm{PhD}$ programme. Such research interventions from higher education studies provide an intervention in andragogies and supervisory methods. Such an integration and intervention have traction and methodological rigour in teacher education (Brew and Saunders 2020). In the doctoral space, such connections are even more important. An implicit and hidden curriculum undergirds the PhD. The best of teaching and learning - and supervision / advising incorporates explicit instruction. This is particularly important when discussing the tacit learning through and from academic socialization. For international students, ${ }^{1}$ students returning to the programme after a gap between degrees, women, transgender students, and students with an impairment, it is challenging to negotiate the assumptions of a doctorate. The structures are geared for young, able-bodied students, straight out of an undergraduate degree, who will continue their education in the regulated environment of a lab. The overwhelming majority of students are not located or derived from this group.

Becoming an academic requires socialization, and the doctoral degree is a pivotal moment in this transition from student to researcher (Gardner \& Mendoza, 2010). Yet the generalizability of individual experiences in past decades for the present is questionable. There are - indeed - dark sides of the university as both an educational experience and a workplace (Bengtsen \& Barnett, 2016). Overt attention to core competencies (Durette, Fournier, \& Lafon, 2014) or generic or transferable skills are important. But it is also key to arching out of a supervisor's experience, to understand the student and to shift andragogical expectations (Elliot, Baumfield, \& Reid, 2016).

To enable a diversity of pathways into and out of a doctoral programme, while maintaining international standards of research and attention to national priorities, necessitates a careful, dynamic, inclusive and robust communication system. It must provide multiple, resonant interventions for part time students to deploy when professional development or an infusion of fresh ideas is required, a recognition of the specific challenges in xenophobic times for international students, meaningful interfaces for researchers working at a distance from a campus, diverse methodologies in post-disciplinary times, and an honest presentation of career goals. This diversity of motivations and aspirations must also be managed alongside the variable quality of doctoral supervision / advising. The gift, if this communication system is effectively constituted, is a socially just community that can create peer support between students and a robust professional development system that can offer learning and employment opportunities if and when required. To create this open access model of teaching and learning, attention is required on the development of a bespoke and specialist component of Media Studies

1 I note the remarkable analysis conducted by Dely Lazarte Elliot, Vivienne Baumfield, Kate Reid and Kara Makara, "Hidden treasure: successful international doctoral students who found and harnessed the hidden curriculum," Oxford Review of Education, Vol. 42, No. 6, 2020, pp. 733748 


\section{PhD Media}

' $\mathrm{PhD}$ media' is a phrase summoned with potential and promise. $\mathrm{PhD}$ media slice across other media platforms and interfaces. Determined and defined by the audience of the platform and the content targeted for them, $\mathrm{PhD}$ media incorporates monographs, academic articles, grey literature, journalism, social media posts, blogs, audiobooks, podcasts and the spectrum of screen-based media. It is specific and honed for a disintermediated audience using multiple modes of reading, writing and engagement. For example, Twitter - or indeed the Twitterverse - is large. It summons abusive trolls, bots, the al-right, the determined if fickle left, and an array of interest groups. Hashtags offer some mode of organization. It is chaotic, but useful when organized. The hashtag \#phdchat is a useful structuring device to manage the chaos. Increasingly journals, professional and academic organization and scholars have Twitter accounts. The best use of Twitter is to push and pull content. Scholars can post innovative articles and ideas. PhD students can pull materials that are suitable to their needs at distinct points of their candidature. Further, they can disseminate their own research outputs. This is a form of networking, without the expense and inconvenience of a conference. High quality content is being shared on twitter. Strong relationships are being formed. The two challenges of twitter remain discipline to ensure that engaging with the interface does not take time out of research and sorting through the cacophony of nonsense to find quality information about ideas. Also, it is important to avoid - block without hesitation - the trolls, bullies, egomaniacs, complainers and pessimists. The $\mathrm{PhD}$ is a difficult social and intellectual space. To focus on its media capacity is productive and useful. Therefore, the next part of this article drills down to a specific interface and a mode of building community, communication and connection for PhD students. The movement from the third to the first person accompanies this movement.

\section{Why a PhD Vlog?}

Communication and community require continuity. A weekly vlog is a commitment. It is a cycle of production that is difficult to maintain in contemporary academic life. Maintaining this regularity reveals surprises and challenging, errors and missteps, but also deep, profound and international engagements with doctoral students in my university and far beyond it. I chose a weekly vlog to communicate with my students at Flinders University. It was not an accidental selection. I had occupied management and leadership jobs for the decade before I came to Flinders University. These management posts required engaging with academics over multiple locations. In the United Kingdom, the geographical spaces between the campuses - Brighton, Eastbourne and Hastings - were not great. For my post based in regional New South Wales, the campuses spanned the regional cities of Bathurst and Dubbo, and a campus in Burlington in Canada. The multiple time zones and tight windows of overlap in the working day required digital solutions to analogue problems. Considered matrices of asynchronous and synchronous media bundles were deployed. Problems were more localized in my management post at the University of Bolton. But with a permanent revolution of restructures, strategic plans and visions statements, staff required stability, support and community. For these posts, there was also an institutional imperative, with pending entries to the Research Assessment Exercise (RAE), Research Excellence Framework (REF), and Excellent in Research Australia (ERA) requiring demonstration of - depending on the system - 'esteem,' 'impact,' 'engagement' or 'environment.' 
To build this culture, after I arrived at Brighton, I started to send weekly staff emails every Friday morning. When I arrived, the staff group were not research active, so it was necessary to re-engage them with an international scholarly community and increase the connection and reading scope into high quality work and writing. The time imperative for RAE entry was also pending publications would have to be written and published at speed. These weekly emails provided links to journals wanting articles, innovative research pieces that had emerged, and podcasts I was recording with staff. They would gain confidence in the expression and dissemination of their research.

Podcasts were also part of this portfolio of weekly materials. I have recorded weekly podcasts since 2006, building on my deployment of analogue sonic material for teaching and learning since the late 1990s. Through sound, staff could share the story of their research and find new audiences. This combination of media interfaces and links created a research culture from a baseline. It demonstrated the value of weekly communication and social media to showcase research. Upon my arrival at the University of Bolton, different problems emerged. A volatile university, staff members were continually being 'restructured' out of the organization. The curricula had similarly been 'restructured' and research was seriously undervalued at Bolton. Many of the academics did not have PhDs. It was necessary once more to 'do something.' A Research Excellence Framework was about to be submitted and few of the staff had reached the threshold for entry. Once more, weekly emails, sharing staff research and podcasts about their publications, alongside showcasing innovative journals, built an intellectual community in an incredibly volatile institution. From this matrix of support, the REF result emerged from sharp and defined entries, creating a better outcome than many of the better funded institutions in the north west of England.

Upon my arrival at Charles Sturt University, a different suite of problems emerged, involving time and space. Besides the diverse time zones in Canada and Australia, there were profound distinctions between the bustling urbanity of Burlington, just outside the global city of Toronto, and the specific rural and regional complexities of Bathurst and Dubbo. From these differences, the question was how to build a research and teaching community into a school and into a community that was based on respect and partnerships. To add to the complexity, this was a School of Education. The series of disciplines included within this title - from physical education to inclusive education and early childhood to higher education studies - made the creation of a teaching and research culture very difficult. The qualifications, experience and research competence of the staff were variable. Therefore, the weekly emails and the podcasting of the weekly school seminar provided a space for staff to grow, read and develop in a community of safety. The strong advantage of these podcasts is that these regional universities gained strong international branding and profile that would be beyond the reach of a small city.

Research communities were created through regular weekly emails, podcasts, sharing of publications and success. The building of an intellectual community, including connections between academics and PhD students, also enables outreach and new readerships from these isolated research environments. Therefore, before considering a video series for $\mathrm{PhD}$ students at Flinders University, I had a history of building intellectual communities through digitization, over space and time, for research outcomes, often managing volatile institutions through periods of change.

The Dean of Graduate Research role is rare. Only one exists in our universities, and it is the only leadership post left in our institutions that requires high level - and equal - ability in both teaching and research. 
Pathways to the $\mathrm{PhD}$ must be understood. The andragogy of doctoral supervision is a delicate and complex entity, requiring a grasp of diverse supervisory teaching modes through all disciplines. Governance and regulation are required, alongside a learning-led research imperative and strong communication skills. Needing to balance teaching and research in unbalanced intellectual times requires authenticity. Expertise in this job cannot be faked. I describe this type of post as the goalkeeper of the university. There is only one in the university. If the team of academics is playing well, then we are invisible. If problems with quality assurance emerge, then this role emerges from the shadows to handle a crisis, often at short notice. The challenge for this role at this point in history, is that the consequences of universities in 'crisis' - or the Zombie University - is that the meaning of leadership is volatile and uncertain (Buller, 2013).

As I was preparing to take up this post, I reflected on my previous use of media. I would send a weekly email to students highlighting research. I would conduct weekly podcasts with students about their research. But I then realized that something was different and required different media choices. One thirds of the students enrolled at Flinders live outside of Adelaide. One third of the Flinders students were part-time. They were not the same third. I discovered two students in Tennant Creek - Melanie and Heather - studying in a town two thousand kilometres from their home campus. Therefore, with Melanie and Heather in mind, I started to explore the problems of the distance doctorate. How could I 'be' a dean of graduate research when so many students were fractured from the campus and then students were siloed into their separate disciplines? Students spanned in age from 23 to 90 . How could support be tailored for the part time students who were most likely to attrite because they did not feel connected to the campus. How could I care for the hundreds of students completing their theses from rural, regional and remote locations, and internationally? Using media interfaces, how could students feel special, distinctive and 'heard,' while also building an intellectual community? A blog would not create that personal connection, and there are fine PhD blogs in existence from the Thesis Whisperer (2020) and Pat Thomson (2020). Visuality was required. A post-textual connection was necessary.

In answer to these questions, I realized with some horror that I would have to switch my comfortable media platform. I could continue to use sound and podcasts, but they would be a secondary medium for this post. I would still send the weekly email - but it would have to convey different content. I would need to be visible, as if in the same room. I realized video was the answer. Visual media are multisensory. A gaze is exchanged through the lens. Intimacy is present and it creates a connection between a dean and a student community, even if they have never and may never meet.

Video became the answer to many of the administrative, management and leadership questions emerging through this new post. Most of these problems were invisible, and not actually logged as problems. Part time candidates, regional students, older scholars and a disconnection between researchers in disparate disciplines are important issues - and people. These challenges were gifts and opportunities and a way to critique - and strongly - the deficit model of teaching and learning that marinates doctoral supervision and advising. Homology dominates. Supervisory training often features the Tourette's-like mantra that commenced this article: "When I did my PhD..." In few areas of life would we generalize on the basis of a single data point. Therefore, video became a strategy to confirm and validate the diversity of students in the contemporary $\mathrm{PhD}$. This choice arched beyond role modelling. It was an active intervention in the assumptions about the identity of the doctoral student in terms of age, funding, race, sexuality, gender, disciplinary background, and class. 
After deciding on the platform, the next set of choices revolved around the type of video to be produced. Visual media are hot and multi-sensory. They are immediate and quickly create a presence. They build connections and community. In my case, it also signified a change of leadership. A new dean was creating a new communication system. This change agitated with what David Stanley described as the platform university: "a physical space that facilitates the interactions between teachers and students" (2019, loc 449) Visual media are located on a continuum, from a simple digital storytelling arc, aligning photographs to music, to a Hollywood blockbuster. From this range of options, this video would have to be produced around my daily tasks as Dean. It needed to be efficiently written, delivered and disseminated. I could not lose a day or a morning to create them. There was no budget, and no staff to offer any assistance for researching, writing, editing or disseminating. But these constricting frames had to be mitigated through a careful consideration of the targeted audience for the videos.

Interface selection, as twenty years of media literacy theory since the New London Group has confirmed (2000), requires a considered understanding of the literacy of the audience, rather than the capacity of the media. Therefore, the genre or mode of communication needed to be tethered and shaped to suit the needs of diverse PhD students. These students had little time, were squeezing research around personal and private responsibilities, and were also located in the smallest country towns and the largest global cities. Internet quality was variable, as was the positioning of media in their lives. With these considerations and limitations in place, I selected a vlog. The informality was important, confirmed by the conversational tone, the capacity to record and disseminate at speed and to claim scholarly space. As a woman, a humanities scholar and an Australian, I am the exact opposite of a triple threat. Therefore, it was important to be centred and demonstrate the value of women and intellectual culture. The vlog series was an enterprise that sliced through anti-intellectualism, sexism, and the marginalization of the humanities and social sciences in Australia. The visuality had a purpose. Also, the informality was important, so that it had a diary quality, capturing something of the day in the life of an academic. Also, mobility and regularity were key factors. I wanted to be able to film the session wherever I was in the world, to meet and interview interesting people, and be efficient. The goal was to set up the camera quickly, press record, deliver content in one take, edit and upload the material to an Office of Graduate Research YouTube channel (2020). The meta-lessons from this tumbling of limitations, priorities and challenges when considering the configuration of a video - or vlog series - became clear:

Be clear in the configuration of the audience. What are their literacies, priorities, limitations and strengths?

Use the audience needs to shape and frame the goals of the media production, recognizing the financial, spatial or time-based restrictions.

Be clear on the meaning of the production and the motivation to undertake it.

Through the weekly production cycle focus on the big picture of the project. What is its value? To whom? Why?

Upon assembling these questions and answers, the vlog was the platform that accomplished most of these imperatives. It was an unusual word and genre. But there was a reason to summon it. A video blog is shortened to a vlog. It is a mode of visual media, delivered digitally, that replicates and enhances the communication system of blogs. Vlogs became popular through the arrival and growth of YouTube, since 
its arrival in February 2005. Vlogs are delivered in regular instalments and are informal in tone, to enable a smooth connection with a community, no matter how small. These vlogs, once housed in YouTube, can be disseminated and triangulated through other social media platforms, such as LinkedIn, Twitter and Facebook. A YouTube channel also allows a direct connection with viewers through a subscription model. The dissemination strategy is free and open access, so they are valuable for academics wanting to reach new audiences with their research. Therefore, it is no surprise that vlogs have gained increasing use in both education and health, sharing stories beyond disciplines and the university community. Research demonstrates the incredible value of YouTube communities in managing chronic illnesses. What these health and education vlogs share is the creation of an online community that builds over time.

Vlogs do not target large groups. They are effective in niche and bespoke areas, like PhD communities. They configure a deterritorialized audience that adds value, meaning, relevance or community to people's lives. The informality of the platform matters. I could have chosen something more 'professional' or 'academic' - borrowing from the lecture format. But I decided on a vlog as it would enable variable lengths, topics and a conversational delivery. It was important that our students - particularly the regional, international and part-time students - saw their dean, felt comfortable with the Office of Graduate Research staff and were connected to their campus, even if they were geographically separated. Consistency of delivery was the key. I wanted to create a relationship with students who are frequently forgotten or marginalized in the contemporary university, particularly part-time, regional and international students. My two students in Tennant Creek - Heather and Melanie - were always in my mind. Whatever else was happening in their lives, once a week there would be an infusion of ideas in their inbox. Podcasts, or sonic media more generally, would not have actioned the immediacy or connection. Visuality was required.

The next step in my planning was challenging. I did not know if it would work. I wanted the students our community - to not only be involved or connected, but to select the vlog topics and ideas. There is much talk of student-centred learning. However, it is much tougher - and so much more valuable - to allow the $\mathrm{PhD}$ students to express their needs, fears, topics of interest and challenges. My concern was if I could transform their requests into meaningful content. I also wanted to interview and talk with our students and interesting scholars from around the world. Diversity was my priority. I wanted to use the power of visual media to blast the assumptions of the identity of $\mathrm{PhD}$ students far beyond the young, white men in the sciences. This component of the vlog has been successful. The diversity of students presented through the vlog has provided both insight and inspiration for people around the world considering a higher degree.

In theoretical terms, I was applying my 3D model of the media: digitization, disintermediation and deterritorialization. While the meaning of digitization is clear, disintermediation refers to the removal of mitigating stages between the producer and the consumer. I did not need to rely on a university marketing department in difficult times for international higher education to edit, produce or release the product. The vlogs are also deterritorialized. Carried by YouTube, they move through space with ease, so that students in Tennant Creek, Dublin, London Ontario, London England, Auckland and Alice Springs are part of this community. 
I was also entering the debate about the political economy of higher education at the point where Jordan Peterson was using his stature as a white, male academic to silence and exclude the voices of others. I was intentionally narrowcasting, not broadcasting. I was constructing Unpopular Culture. This term like postcolonialism - is important. The 'un' prefix, like the 'post' is important, as it problematizes the word that follows it. As shown by the repetitive use of the word 'crisis' in titles from Higher Education Studies, the university sector is troubled in terms of its purpose, its standards, its funding model and its leadership. Further, through oddly constituted national research review or evaluation exercises, disciplinary boundaries have been reinforced and calcified through the behaviour of insular intellectual gatekeepers. In doctoral education, such tendencies and structures are dangerous as they block innovation, transgressive thinking and post-disciplinarity. Therefore, a Dean of Graduate Research must occupy an unstable but productive role, to shatter brittle academic silos, activate postdisciplinarity, summon an intellectual culture, and affirm the international mobility of ideas. Miyase Christensen and Andre Jansson confirmed that,

Global mobility is changing the face of human geographies while politics is being reconfigured with old allegiances and 'fear of the new' ushering in neo-conservatism, on the one hand, and saturating life with new sensibilities and hope, on the other $(2015$, vi)

Mobility is not benevolent or even neutral in its application. It must be framed, shaped and textured to summon considered relationships between form and content. The imperative to read widely and write to provoke, transform and transcend is not encouraged or validated in universities, peer review processes or national research reviews. Therefore, vlogs can prise open a new theoretical space to explore the meta$\mathrm{PhD}$ in a post-industrial age.

The 'woman problem' was also a key determinant in the decision making to deploy visual media. Women in our universities, let alone female academics, are invisible. Social media are cruel to women, and corrode the space, the experience and confidence of women over thirty. As an experienced media performer, I expected some commentary about my face, hair, body or voice, or indeed my right to occupy space. In the first month, there was some kick-back from white male professors in their sixties. Comments were emailed to me. A selection of these talking points includes the ontological question, "Who do you think you are?", followed by "Don't tell my students what to do," and my personal favourite, "You need to stop with this ghetto talk." These statements convey narratives about women in our universities, and the challenges of occupying a position of authority and expertise. But also, disintermediated sources like vlogs allow groups outside of dominant cultures to 'speak back' on their own terms. New spaces, voices and views can be summoned. In all these cases, I responded with decency and respect. In the case of the scholar questioning my 'ghetto talk,' I asked for further clarification. It became clear that this senior scholar thought I was 'low class,' blurring race and class, and therefore positioned me in the ghetto with Tupac. However, the agenda of this vlog series was overt and unapologetic diversity. This was not popular culture. It was not broadcasting. My imperative was to develop deterritorialized, narrowcasted, unpopular culture, targeted at a very specific group of scholars: research masters and PhD students at Flinders. For viewers to be confronted by their assumptions about life, academia and doctoral education, to view different accents, faces, bodies, views and approaches, is a powerful force and indeed the foundation of an intellectual life. 
There were early calls to simplify and shorten the material, and - bizarrely - add PowerPoint slides. However, I confirmed the decision to capture what vlogs do best: embrace the diversity, welcome the difficulty and disconnect from any interest in the size of the audience. If one person who requested the vlog topic gained some insight through it, then it was a success. If one person felt connected to the university, then the project was meaningful. Such words are important to this project. Relevance. Meaning. Connection. Community. To enable such words, some key stages were required on this learning-led project.

Construct clear aims and goals

Focus on 'the why' of the vlog

What is the theoretical frame around your work?

Be personally robust

Consider what success means for this project

The key through this reflection cycle was not to be dragged into other people's personal views or opinions. With these frames and decisions solidified, new intellectual spaces can be created.

The type of media interfaces best suited to vlogs are distinct from other visual interfaces. Vlogs require efficiency and an ease of use. I needed a recording and editing system that was quick, intuitive and could be completed without the assistance of others, and often while mobile and away from home. I was also aware when I featured guests on the vlog that placing a lens in front of someone's face is confronting. Therefore, setting up the camera quickly and recording cleanly, without delays, errors or interruptions, was a priority. My vlogs started with the Flip Camera, which was ideal for vlogs. A small camera with software resident on the platform, it was excellent. But a year into the vlog, Cisco not only bought the Flip, but killed it. Through this corporate takeover, I lost hardware and software. I moved to the Zoom camera, as I had used their microphones for a decade. This camera was adequate, but the fisheye lens did not match the excellence of the sound. Also, the resilience of the focus was problematic, so I moved to a compact Sony which has provided successful, with sufficient flexibility. Vlogs do require distinct technological choices as the software and the hardware must be robust, intuitive, quick to deploy, portable and simple to edit.

While form matters to this discussion, so does content and the mode of delivery. The conversational tone was intentional, and appropriate to the student-centred enterprise. It commenced and remains a $\mathrm{PhD}$ jukebox where students request the topics of each session. Students around the world have suggested the overwhelming majority of the vlogs. The others were required as steppingstones to the student requests. For example, I was asked to discuss the most common errors emerging from a $\mathrm{PhD}$. To present that session required some material on the information scaffold. Similarly, to explore the blue and green economy required a discussion of the political economy. The key challenge to address early in the process is that students did not know what they did not know. They do not know what they do not know. Many of the requests were soft, probing their feelings and emotions. While these requests were respected, it was also important to stop the vlog series becoming a version of Oprah for the doctoral candidate. Therefore, feelings were validated, but intelligence and academic growth were more important. Agnotology - the 
propagation of ignorance (Block, 2019) - is frequently maintained through the confusion of experience and expertise. Through disintermediation and deterritorialization, weak views can be strongly held and shared. This relationship between the personal, political, professional and academic remains volatile in a higher education system struggling to find a purpose (Hartmann, 2019). It is important for scholars, before they move into a vlog series, that such matters are addressed and resolved. As shown by Koivunen, Kyrola and Ryberg, vulnerability is transforming in its meaning and political imperative (2018). International higher education is so volatile, that in a series there will be personal and professional challenges that have to be resolved in real time.

The research I conducted each week, from the topics suggested by the students, was uneven in its quality. Most of the topics veered towards some mediocre management theory, disturbing self-help, or dated educational psychology. This is not a high-quality intellectual frame. Therefore, each week it was both important and necessary to provide an infusion of high theory, to offer an inspiration for some of the most important and controversial scholars in the world. For example, Guy Standing's The Precariat was used as a frame for a vlog to address the adjunct academy. Perhaps the best example was in the "Overwhelmed" vlog. This topic could - very easily - have teetered into self-help 'gurus.' Instead, I commenced the vlog with an infusion of Thomas Raymen and Oliver Smith, and their developing concept of "deviant leisure" including their new theorization of risk (2019). This composition of ideas, including 'tips and tricks' for productivity and efficiency while contained in a complex and challenging intellectual frame, was a difficult combination to create and sustain. Through the STEM-ification of universities (Sharma, 2015), this vlog series occupied an intellectual function, a thinking function and - indeed - a radical function. Visibility was granted to people, ideas, concepts and theories that are rarely validated by the dominant intellectual culture.

Student-led learning is a cliché. It is also hard work. Student autonomy is integral to any doctoral programme. Yet how this autonomy is created - beyond neglect of the student-is unclear. Undergraduate education has a stronger suite of theories to deploy (Duarte, Leite, \& Mouraz, 2016). While much of the focus in the PhD involves the development of an independent researcher, the curricula decision making necessary to enable that autonomy is neither specified nor embedded into the programme. The atomization of each candidate means that methodologies for teaching and learning are not shared. Research requires the capacity to challenge and transform research design, research questions, methodology, ontology and methodology. Students provided an array of unusual requests and I tried to configure strategies to enable them. Every request was placed in my vlog file which, as I write this article, is now 2103 pages and 402,038 words in length. From the multiple requests, I work on the topics. That means there is between ten and twenty vlogs being prepared at a particular time. A new article or book, or an interesting event or story, often pushes one of these vlogs-in-preparation to the front of the queue. Some emerge directly from a request, but they also are requested in response to other vlogs. Therefore, some organic - if haphazard - information scaffolding emerges. A strong example is from John, a frequent correspondent. He asks for very complex and intricate requests. John started the social justice quartet with a vlog on how to be a homosexual man in a doctoral programme. That became the foundation of the series that was deeply unpopular and confronted students about men, women, sexuality, families, work, leisure and education.

From the student requests that are amalgamated with contemporary research, a full script is configured. Some are written in two hours. Some take a few weeks, as exemplified by the self-plagiarism session. It 
was intricate and complex and was - in effect - a refereed article creating new knowledge. I then - literally - cut and pasted them onto cards and learned the script during my workout at the gym each morning. Ten hours of memory work was used, followed by a single-take recording session, and thirty minutes to edit and upload the session.

This responsive process between students and their dean has been evocative and exciting. It has also created innovation. I would not have considered any of the topics suggested by students from around the world. It remains a learning-led process. There have been challenges and this long-term research project about and for research students has required careful - if rapid - decision making through the process. This series has captured many of the andragogical change of the twenty-first century. Nicole Mary Rege Colet described it as, "letting go of a teacher-centric knowledge-dissemination model to summon up a studentcentric learning focussed approach" $(2017,72)$. This statement captures a movement from teacher to student, but also from disseminating disciplinary content to the building of learning architecture and meaning systems. Learning emerges in a context. These vlogs offered an opportunity to create new learning architecture for a volatile higher education sector.

The most complex series of decisions, particularly for an academic woman operating in the online environment, is balancing the relationship between the personal and the professional, the social and the scholarly, the self and the intellectual. To shape these delicate strands of difference through a weekly video is complex. But a series of steps enabled the decision making at the start of the project:

Think and operate internationally

Transcend disciplines and silos

Build an inspirational intellectual community

Work with the powerful and transgressive scholars and ideas

Relish the debate and operate within un/popular culture

These principles aligned to create a safe space for ideas, models, intellectual debate and discussion. Students can hear unusual ideas that they may disagree with, from different disciplines. But this is a way to enable post-disciplinary conversations or - at least - transgressive thoughts. This was a learning space, but also an opportunity to provoke, challenge and create.

The informality of vlogs creates specific challenges in the configuration and presentation of content. We live in an over-sharing culture, photographing meals and posting them on Instagram. But part of this $\mathrm{PhD}$ vlog project was to create connection, communication and community. Isolation, and assuming that a student does not belong to a wider group or community, creates fear, doubt and anxiety. Recent research demonstrates that the mental health concerns amongst $\mathrm{PhD}$ students are high. A few students are killing themselves, as exemplified by the tragic case of Jessica Small, a $\mathrm{PhD}$ student in anthropology at the University of Kent. She killed herself in October 2019, because of bullying, a toxic lab and her fellow $\mathrm{PhD}$ students mocking her for not attending an elite school or speaking with a particular accent. 
Therefore, a key part of the vlogs was always the creation of real, authentic and meaningful connections. These alignments are built through the sharing of stories and storytelling. After requesting the permission of students, I always name the people that request the vlog. It is a reminder that $\mathrm{PhD}$ students are people and the vlog is an interface to communicate, share, understand, disseminate and share. Obviously, I am also a dean, professor and international researcher. The relationship between public and private remains negotiable. But student stories matter. The lived experiences of $\mathrm{PhD}$ students are often buried or marginalized. They are ephemeral, washed away as one cohort completed their thesis and the next generation is enrolled. For the YouTube channel, the students are the stars and their needs are a priority. Yet the dance between public and private remains complex.

I am a private person. Students do not have my mobile phone number and my house is a sanctuary that is closed off to 'entertaining.' However, it was necessary to present the brutalizing toxicity and startling beauty of higher education. I was not creating a marketing campaign through the vlogs. Honesty was the key. Universities are complex, intricate and volatile organizations. Therefore, presenting that reality was an important imperative. The impact of student-led learning is that the supervisor / teacher's position also changes. Over four years of writing, recording and releasing weekly vlogs, the system has operated effectively. Thousands of PhD students have completed - and quickly. Thousands have enrolled with clear expectations and momentum. Thousands of graduating students approach the workforce understanding casualization, the precariat conditions and how to be interviewed and be competitive. The goal is not to create a culture of clones, agreement or standardization. Indeed, the imperative is the exact opposite: relish the diversity and the differences, grasp the capacity of diverse ideas and disciplines. Argument, debate and the valuing of meaningful intellectual culture are promoted.

This has become a learning-led research project. The vlog series started with some theories to test and trial. Very quickly, my audience of two in Tennant Creek became larger and international. The vlogs are now sitting at nearly two million views. Even through this transformation of scale, it remains a learningled, disintermediate video project to create community, connection and communication. There have been challenges and surprises. There has also been tragedy and when I review these vlogs, this adversity will punctuate this memory. The death of my husband, the senior academic Professor Steve Redhead, occurred during the series (Brabazon, 2019). He features in four of the sessions, and he is at his brilliant, engaging and humorous best. Steve was diagnosed with pancreatic cancer in the last week of June 2017. We had recorded the vlog - 'blog to book' - the month before this diagnosis. Steve wanted no treatment and few options were and are available through this illness. He decided to maintain privacy, complete his books, book chapter and articles, and did not want pity or sympathy, or his research being treated through the lens of disease. He wanted to spend his last few months with me in privacy. I was able to deliver on that request. But his illness and death - and the secrecy of it - had a huge impact on these vlogs. From Vlog 67 on Altmetrics through to Vlog 202, the digital doctorate, I managed the dean role and cared for Steve in secret. Personal memories soak these sessions. The first vlog of 'The three monkeys' series on Epistemology was recorded after I had been with Steve in an emergency room all night. I sped home on the Sunday morning, showered, filmed the vlog and returned to the hospital. The locations of the vlogs moved away from the house to ensure Steve could sleep undisturbed. Life - and the public and private division of responsibilities - became complex. My physical state in some of these vlogs is quite uneven. Ironically, the vlogs Compartmentalization and Excuses are particularly difficult to watch. 
For those considering an academic vlog with a regular schedule, this tragic lesson is an important one. Dreadful events will emerge in a professional or personal life. Choices are available, but those choices will impact on the capacity to deliver regular, high quality content. I could have given up the schedule, and in my case that may have notifying viewers that something was wrong, perhaps with Steve. Indeed, he was involved with these sessions right until the end. I always read him the first draft of every script, including the digital doctorate vlog. I recorded that during his last full day in the house. He died three days later. Therefore, these sessions - for me - convey the accidental biography of an illness and a death. There are also important and inspirational stories. Dr Dani Milos ran vlog 102 with me, and we delivered it the day after Steve's death. I wanted to record this session to provide a space in the following days to manage the vagaries and details that emerge after a death. Dr Milos, although shaken, was incredibly courageous. We delivered that content. If that vlog had been missed, it would have been simple to conclude the series at this point.

Steve Redhead's death, although the worst event to ever happen in my life, did present gifts to me, just as his life presented gifts. The resilience series, which conveyed the reification of the word and its project, has been used in social work education in the United Kingdom. The vlog on death is another example. Thousands of students contacted me, but also used this video to share with their friends, colleagues, supervisors and advisors to explain how losing a spouse transforms a life and a candidature.

This personal intervention is meaningful. I never thought that more than half of the vlogs would be produced without Steve, or that this series would shadow his illness and death. That is - perhaps - the nature of social media and being a woman in academic life. The personal is political. The personal is academic. Students were also able to share a moment of great happiness as I married Professor Jamie Quinton and a series of vlogs were recorded on our honeymoon.

\section{Endings and Beginnings}

This learning-led project has configured a bespoke and important new genre: $\mathrm{PhD}$ media. It confirms the diversity of $\mathrm{PhD}$ students in location, discipline, age, disability, goals and expectations. Vlogs capture this diversity, interviewing extraordinary students expressing their achievements and disappointments. Fascinating international researchers can be interviewed. Controversial post-disciplinary areas like the blue economy, green economy and the political economy can be explored.

$\mathrm{PhD}$ media, for my university, became the foundation for the Digital Doctorate, a project to create a parity of experience for students, whatever their geographical location. An added advantage, which became profoundly important in 2020, was to maintain connection, community and communication through Covid-19. This was a twisted reconfiguration of what Slavoj Zizek described as the "new dark ages" (2014). But further, the vlogs provided an interface to summon, probe and explore what Steve Redhead affirmed as "new post-disciplinary theory and a new politics of theory" (2017). Through shutdowns, lockdowns, social isolation, fear, sickness and death, digitization became the singular strategy to maintain a community. This vlog series, through difficult times, asks us to ponder the narratives of higher education, and the stories that we are telling ourselves about doctoral education.

In universities, like the rest of society, the $\mathrm{PhD}$ student is rarely centred, or at the centre of any discussion. Through PhD media, the student becomes the star of the programme, with their hopes, views, 
disappointments and the future at the centre. Vlogs provide a way to see difference and slot a slice of content into a research life that is convenient, perhaps confronting, but hopefully useful. It can provide just-in-time training, or just-in-time reflection. But through the Three $\mathrm{Cs}$ - communication, connection and community - a new future of higher degrees may be summoned through the midwife of social media. This future of the $\mathrm{PhD}$ is already here, shattering the hierarchies of the sciences over the humanities, the young over the old, elite knowledge over popular culture, and the empiricism over the theoretical.

\section{References}

Bengtsen, S., \& Barnett, R. (2016). Confronting the dark side of higher education. Journal of Philosophy of Education 51 (1), 114-131.

Block, D. (2019). Post-truth and political discourse. Gewerbestrasse: Palgrave.

Brabazon, T. (2018). The deficit doctorate: Multimodal solutions to enable differentiated learning. International Journal of Social Sciences and Educational Studies, 4(5), 52-70.

Brabazon, T. (2019). Memories of the future: Post-Steve Redhead, cultural studies and theory for a stillborn century," from Redhead, S., The End-of-the-century party (second edition). Manchester: Manchester University Press.

Buller, J. (2013). Positive academic leadership: How to stop putting out fires and start making a difference. San Francisco: Jossey-Bass.

Brew, A., \& Saunders, C. (2020). Making sense of research-based learning in teacher education," Teaching and Teacher Education, 87, 1-11.

Christensen, M., \& Jansson, A. (2015). Cosmopolitanism and the media: Cartographies of change. Houndmills: Palgrave.

Colet, N. (2017). From content-centred to learning-centred approaches: shifting educational paradigm in higher education. Journal of Educational Administration and History, 49(1), 72-86.

Durette, B., Fournier, M., \& Lafon, M. (2014). The core competencies of PhDs, Studies in Higher Education, Volume: 1-26

Gardner, S., \& Mendoza, P. eds. (2010). On becoming a scholar: Socialization and development of doctoral education. Sterling: Stylus.

Google (2020). "When I did my PhD," Google Search. February 17:

https://www.google.com/search?rlz=1C1SQJL_enAU860AU867\&biw=1536\&bih=754\&sxsrf

$=$ ACYBGNQRU1WICNBpgbiraNmgSEB55HFkcQ\%3A1581874171226\&ei $=-$

3tJXtOsDc2vyAPa7LawDQ\&q=\%22When+I+did+my+PhD\%22\&oq=\%22When+I+did+my+ PhD\%22\&gs_l=psy-ab.3..0i22i3012.9206.12074..12744...0.1..0.222.421.0j1j1..........1..gws-

wiz.......0i71j35i39.HbDYp21KSGg\&ved=0ahUKEwiTlrjAzNbnAhXNF3IKHVq2DdY4ChD h1QMICw\&uact=5

Hartmann, E. (2019). The future of universities in a global risk society. Globalizations, 16(5), 717-738.

Koivunen, A., Kyrola, K., \& Ryberg, I. (2018). The power of vulnerability: Mobilising affect in feminist, queer and anti-racist media culture. Manchester: Manchester University Press.

Levecque, K., Anseel, F., De Beuckelaer, A., Van der Heyden, J., \& Gisle, L. (2017). Work organization and mental health problems in PhD students. Research Policy, 46(4), 868-879.

New London Group. (2000). A pedagogy of multiliteracies: designing social futures, from B. Cope and M. Kalantzis (ed.), Multiliteracies: Literacy learning and the design of social futures, South Yarra: Macmillan.

Office of Graduate Research Channel (2020) YouTube:

https://www.youtube.com/channel/UCwdaNGhdSAwzdztgLTqyhgA?view_as=subscriber

Raymen, T., \& Smith, O. (2019). Deviant Leisure: A Critical Criminological Perspective for the

Twenty-First Century, Critical Criminology, 27(1), 115-130. 
Redhead, S. (2017). Day in, day out: pop goes the city. Palgrave Communications. DOI: 10.1057: https://www.nature.com/articles/palcomms201736

Sharma, A. (2016). STEM-fication of Education: The Zombie Reform Strikes Again. Journal for Activist Science and Technology Education. 7(1). https://jps.library.utoronto.ca/index.php/jaste/article/view/26826

Stanley, D. (2019). Alternative universities: Speculative design for innovation in higher education. Baltimore: Johns Hopkins University.

Thesis Whisperer. (2020). Blog: https://thesiswhisperer.com/

Thomson, P. (2020). Patter: https://patthomson.net/

Whelan, A., Walker, R., \& Moore, C. (2013). Zombies in the academy: Living death in higher education. Bristol: Intellect.

Zizek, S. (2014). Trouble in paradise: From the end of history to the end of capitalism. London: Allen Lane. 